\title{
Effects of Unilateral Versus Bilateral Plyometric Training on Endurance Running Performance
}

\author{
Ian J. Greenwood ${ }^{1}$, Anthony D. Kay², Anthony W. Baross².
}

${ }^{1}$ Department of Sport Science, Milton Keynes College, Milton Keynes, United Kingdom.

2Faculty of Health and Society, Sport and Exercise Science, University of Northampton, Northampton, United Kingdom

\begin{abstract}
The purpose of the study was to investigate the effects of an 11-week unilateral versus bilateral plyometric training intervention on isometric maximum voluntary contraction (MVC) knee extensor torque, countermovement jump height (CMJ), running economy (RE) and $3-\mathrm{km}$ time trial (TT) performance. Twenty-seven recreationally trained endurance runners (12 females and 15 males) were randomly assigned to one of three groups: unilateral plyometric training (UPT; $\mathrm{n}=$ $9)$, bilateral plyometric training (BPT; $n=9)$ and control (CON; $n=9$ ). RE, VO2max, 3-km treadmill $\mathrm{TT}$, isometric MVC (bilateral and unilateral) and CMJ (bilateral and unilateral) were measured prior to and after 11 weeks of training (UPT and BPT; volume equated, 20-40 minutes, 2-3 days/week). Separate two-way repeated measures ANOVAs were used to assess within and between group differences in $\mathrm{RE}, \mathrm{VO} 2 \mathrm{max}, 3-\mathrm{km} \mathrm{TT}$, isometric MVC knee extensor torque and CMJ. Following 11 weeks of plyometric training there were significant improvements in in both groups for RE (UPT 5.6\%; BPT 4.9\%, p < 0.01), 3-km TT performance (UPT 2.4\%; BPT 2.5\%, $\mathrm{p}<0.01$ ) and CMJ (UPT 12.5\%; BPT 14.5\%, p < $0.01)$. Additionally, isometric MVC knee extensor torque improved in the unilateral group (14.0\%, p $<0.01)$. No significant differences in VO2max or anthropometric measures were detected ( $p>0.05)$. No statistically significant differences between training interventions ( $p>0.05)$ were detected in any measure. These data demonstrate that UPT and BPT result in similar improvements in RE and 3-km TT run performance in recreational distance runners.
\end{abstract}

Keywords: running economy, 3-km time trial, musculotendinous stiffness, neuromuscular characteristics.

\section{INTRODUCTION}

Distance running performance is dependent on the complex interaction of numerous physiological and biomechanical factors. Physiological determinants include maximal oxygen uptake (VO2max), lactate threshold and running economy (RE) $(3,15)$. RE is the submaximal rate of oxygen consumption (2) or energy cost of running (11) at a given running velocity, with lower values indicating better RE (20). RE can vary by as much as $30 \%$ in trained endurance runners who are homogenous with respect to VO2max (2). Although aerobic factors largely underpin endurance performance, biomechanical characteristics are known to influence RE, which can be improved with plyometric training $(4,5,7)$.

Several biomechanical parameters can affect RE including stride length, lower limb joint angles and neuromuscular factors associated with mechanical stiffness of the musculotendinous system $(20,29)$. Improvements in the latter have been associated with plyometric training (27). Plyometric training involves an eccentric muscle contraction followed immediately by a concentric contraction to allow the muscle to store and return elastic energy $(5,31)$. Studies have demonstrated a $4-8 \%$ enhanced RE following 6-9 weeks of structured plyometric training ranging widely in volumes and intensities $(5,22,27,28)$ in addition to concomitant improvements of $2.6-5 \%$ in $3-\mathrm{km}$ and $5-\mathrm{km}$ time trial (TT) runs $(5,22,23,28)$ in trained endurance runners. Furthermore, a chronic 
increase muscle excitation of the leg extensors from strength and plyometric training have been moderately correlated with increases in running speed and decreases in oxygen consumption at submaximal speeds $(9,18,30)$.

Various mechanisms have been suggested to underpin the potential of plyometric training to influence changes in muscle-tendon interaction associated with better RE and endurance performance. Fletcher \& Maclntosh (11) have proposed that an optimal tendon stiffness may exist which reduces the velocity and magnitude of muscle shortening thereby allowing muscle fibers to optimize their length and operate in a more isometric state. Isometric contractions require less metabolic energy than contractions that result in an active shortening or lengthening for a given force production (11). Furthermore, a reduction in muscle fascicle shortening velocity decreases the number of active motor units and therefore energy cost (12). It is these mechanisms that have been suggested to reduce the energy cost of running following a structured plyometric training program.

Numerous studies have successfully used unilateral and bilateral exercises in a concurrent plyometric and endurance training intervention to improve distance running performance and RE. Bilateral drop jumps have reportedly had a positive effect on $R E$ and time trial performance $(5,25)$. In addition, combined unilateral and bilateral jumps, hops and bounds have demonstrated significant improvements in RE $(22,23,27,28,31)$. However, it is not clear from the available literature whether each plyometric training method individually may offer superior benefits in optimizing muscle tendon unit stiffness in distance runners.

Running is a bipedal sport with phases of single leg support within the athlete's stride therefore the force generated to move the runner forward comes from the propulsive leg individually in each stride $(17,19)$. McCurdy et al. (19) investigated the effects of unilateral plyometric training (UPT) and bilateral plyometric training (BPT) on counter movement jump (CMJ) height and reported greater improvements in unilateral jump height in the UPT group in comparison to the BPT group. RamirezCampillo et al. (24) observed a similar specificity training effect in jump height and distance, where UPT induced significantly greater improvements in unilateral CMJ tests and BPT lead to significantly greater increases in bilateral CMJ performances. Furthermore, Bogdanis et al. (6) reported UPT to be more effective than BPT at increasing the sum of the right and left leg CMJ height and rate of force development. Collectively, these data are suggestive that plyometric training should be reflective of the specific unilateral or bilateral patterns that occur within the sport. However, to date no research has directly compared unilateral and bilateral strength and/or plyometric training on a range of strength, power, and endurance running performance variables. Therefore, the aim of the present study was to compare the effects of UPT and BPT on $\mathrm{RE}$, endurance performance, isometric maximum voluntary contraction (MVC) knee extensor torque, and $\mathrm{CMJ}$ height, in recreationally trained runners.

\section{MATERIALS AND METHODS}

\section{Experimental Approach to the Problem}

This study was designed to address how a short-term, high frequency (2-3 sessions/week) plyometric training program using a high volume affects explosive strength, RE and $3-\mathrm{km}$ TT run performance. Prior to the commencement of all baseline measures, participants were familiarized with all testing and training procedures on a separate day and were habituated to treadmill running in their regular training routines. To standardize recovery status between laboratory visits, participants were verbally screened to check for any undue fatigue. Following initial baseline measures (anthropometric measures, isometric MVC knee extensor torque, CMJ, RE, VO2max, [day 1] and 3-km TT [day 2]) participants were randomly assigned to one of three groups: UPT $(n=9)$, BPT $(n=9)$, and control (CON; $n=9$ ). Experimental groups undertook either an 11week UPT or BPT program alongside regular running training whereas the CON group undertook their regular run training only. All tests were undertaken at the same time of day to avoid diurnal variation in performance with individuals instructed to have a typical pre training snack and be well hydrated (consumption of $500 \mathrm{ml}$ fluid) approximately 3-4 hours prior to testing.

\section{Participants}

Twenty-seven recreationally trained endurance runners (12 females and 15 males; age $=35 \pm 6$ years; height $=1.7 \pm 0.1 \mathrm{~m}$; body mass $=74.3 \otimes$ $15.1 \mathrm{~kg}$; VO2max: males $=53.5 \pm 6.3 \mathrm{ml} \cdot \mathrm{kg}-1 \cdot \mathrm{min}-1$, females $=42.8 \pm 4.5 \mathrm{ml} \cdot \mathrm{kg}-1 \cdot \mathrm{min}-1,16-42 \mathrm{~km}$ run training distances per week consistent in the last 3 months) with no history of plyometric training 
participated in the study. Plyometric training was defined as exercise that exaggerates the stretchshortening cycle to enhance the store and return of elastic energy within the muscles and tendons (5). No history of plyometric training was defined as no previous experience of undertaking a structured plyometric training program and not performed plyometric exercises in the previous 3 months (28). All participants met the criteria of the 'apparently healthy' category, as defined by the American College of Sports Medicine (1). Participants were informed of the benefits and potential risks associated with the investigation, completed a physical activity readiness questionnaire (1) and signed an informed consent prior to the start of the study. The study was approved by the University of Northampton's Research Ethics Committee.

\section{Procedures}

Unilateral and bilateral isometric MVC knee extensor torque

Participants initially completed a five minute warmup on a motorized treadmill (HP Cosmos, Nuffendorf, Germany) at 4-6 km.h-1 followed by a dynamic stretch protocol (6 repetitions on quadriceps, hamstrings and gluteals). Following a three-minute recovery period, bilateral isometric contractions were performed first by all participants on an isokinetic dynamometer (Biodex System 3 Pro, IPRS, Suffolk, UK) with the knee and hip at 90o flexion to ensure consistent internal moment arms and muscle length properties, respectively. The dynamometer attachment was positioned proximal to the ankle with identical positioning used in all experimental testing sessions to ensure consistent external moment arms. Five sets were performed ( $3 \mathrm{~s}$ each) with one-minute rest between sets. Participants were informed that the first two sets were 'warm-up' attempts performed at $50 \%$ and $75 \%$ perceived MVC followed by three maximal attempts. Three minutes later, unilateral contractions (preferred leg only as determined by the leg used to kick in sports) were performed by all participants with identical intensity and rest periods. Data were directed from the dynamometer to a high-level transducer (model HLT100C, Biopac, Goleta, CA) before analog-to-digital conversion at a $2000-\mathrm{Hz}$ sampling rate (model MP150 Data Acquisition, Biopac). The data were then directed to a personal computer running AcqKnowledge software (v4.1, Biopac) and filtered using a zero lag, 6-Hz Butterworth low-pass filter. Bilateral and unilateral isometric MVC knee extensor torque was considered as the peak torques achieved during the three unilateral and bilateral trials, respectively. Participants were given verbal encouragement to give their maximal effort during all trials.

\section{Unilateral and bilateral CMJ}

Following a five-minute recovery period participants completed unilateral and bilateral CMJ tests using a portable electronic jump mat system (FSL JumpMat, Chester, UK) to estimate jump height. During the CMJ tests, participants were instructed to stand on one leg (right then left) for the unilateral test and with feet positioned shoulder width apart for the bilateral test. Participants were instructed to perform a fast-downward movement (approximately 450 knee angle) followed by a maximal effort jump with arms to assist the performance. Participants were advised to land in the same place as take off in each test and had a 3-minute recovery period between the unilateral and bilateral tests. Each CMJ measure was executed 3 times (alternating right and left leg for the unilateral trials, with a 30-s recovery period between all unilateral and bilateral attempts) with the peak jump height for each test recorded. Participants were given verbal encouragement to give their maximal effort during all trials.

\section{$R E$ and $\mathrm{VO}_{2} \max$}

Five minutes later, participants started the $\mathrm{RE}$ protocol on the same motorized treadmill. Participants ran at two submaximal speeds: 10 $\mathrm{km} \cdot \mathrm{h}-1$ (RE speed 1: RES1) and $11.5 \mathrm{~km} \cdot \mathrm{h}-1$ (RE speed 2: RES2) for females and $11.5 \mathrm{~km} \cdot \mathrm{h}-1$ (RES1) and $13 \mathrm{~km} \cdot \mathrm{h}-1$ (RES2) for males (gradient incline set at $0 \%$ ) for 5 minutes at each speed with a 5-minute recovery period between bouts. RER of $<1.0$ was recorded during the RE trials, indicating that a $\mathrm{VO}_{2}$ slow component was not evident for each sample (10). Five minutes later the participants completed $\mathrm{V} \mathrm{VO}_{2}$ max test with an initial speed that corresponded to their final RE speed. The incline was set at $1 \%$ gradient throughout the $\mathrm{VO}_{2}$ max test with treadmill speed increased by $1 \mathrm{~km} \cdot \mathrm{h}-1$ at $150-\mathrm{s}$ stages (1) throughout the $\mathrm{VO}_{2}$ max test until volitional exhaustion was achieved (10:38 $\pm 1: 37 \mathrm{~min} / \mathrm{s})$. $\mathrm{VO}_{2}$ max was determined as the highest 30 -second rolling average $\mathrm{VO}_{2}$ value in addition to respiratory exchange ratio $>1.15$ and heart rate within $5 \%$ of age-predicted maximum. Breath-by-breath $\mathrm{VO}_{2}$ (Cortex Metalizer, Cranley, Birmingham, UK) was collected throughout each of the RE velocities and $\mathrm{VO}_{2}$ max stages. The average $\mathrm{VO}_{2}$ over the final 2 minutes at each RE speed (RES1 and RES2) was taken as the steady-state $\mathrm{VO}_{2}$. Steady-state $\mathrm{VO}_{2}$ was 
defined as less than $100 \mathrm{ml}$ min-1 change during the last 2 minutes at each RE speed (10). RE at each speed was expressed as energy cost $(\mathrm{kJ} \cdot \mathrm{kg}-1 \cdot \mathrm{km}-1)$ (10) thereby allowing for individual comparisons between sex and running speeds. Energy cost was calculated as:

Energy cost $(\mathrm{kJ} \cdot \mathrm{kg}-1 \cdot \mathrm{km}-1)=$

$\mathrm{VO}_{2} \times$ Caloric Eq.

$x$ 4:1839 kJ kcal-1 S-1 BM-1 $x 1,000$

where $\mathrm{VO}_{2}$ is measured in $\mathrm{L}$ min-1, caloric equivalent is in $\mathrm{kcal} \mathrm{L}-1$ of $\mathrm{O}_{2}$, speed $(\mathrm{S})$ is measured in $\mathrm{m}$ min1 , body mass (BM) is measured in $\mathrm{kg}$ and 1,000 is $\mathrm{m} \mathrm{km}-1$.

\section{3-km TT endurance run test}

During a second laboratory visit (48-96 hours later), participants undertook a $3-\mathrm{km}$ treadmill TT (PRECOR TRM833/P30, Camberley, UK) to assess running performance. Following the same warm-up and dynamic stretch protocol undertaken on day 1. participants were given 1-minute to establish a comfortable running speed before the start of the TT. Participants had autonomy over the treadmill speed control and could view distance only on the console display. Participants were given verbal encouragement during the test to give their best $3-\mathrm{km}$ performance and instructed to exert a consistent effort over the fixed distance. Time was measured to the nearest second.

\section{Training Interventions}

\section{Endurance training}

All participants (UPT, BPT, CON) maintained their regular running training (determined by training diary logs) throughout the intervention period. The training intervention was carried out during the general preparation period of the endurance running season.

\section{Plyometric training}

Table 1 shows the 11-week UPT and BPT programs. The progressive overload principle was incorporated into the training plan by increasing total foot contacts each week in a 4-week step loading manner and varying the complexity of exercises undertaken. Participants attended one supervised session each week lead by the author to ensure consistency of exercise execution. The remaining weekly training sessions for each experimental group were unsupervised but monitored remotely on a weekly basis. UPT and BPT participants received exercise video guidance prior to week 1 . Week 1 involved familiarization of the plyometric training programs through supervised demonstration and instruction. All experimental participants demonstrated a good level of competence with the plyometric exercises in the first week of training. All plyometric training had at least 24 hours between sessions and were scheduled at the same time of day ( \pm 2 hours). Prior to each plyometric training session participants underwent a 10-minute dynamic warm up and stretch component (leg swings, ankle bounces, vertical jumps and skips at approximately 50\% maximal effort). Both experimental group's plyometric training volume was matched by participants completing the same number of total foot contact jumps per session and per week. Training details relative to the number of foot contacts are given in Table 1 . Training intensity for both groups was equalized for box jump exercises only through reducing jump height by $50 \%$ for the UPT when compared to the BPT group. All training sessions were conducted on the same training surface (grass and sprung wooden floor). Plyometric training sessions lasted 20-40 minutes and participants were instructed to give their maximal effort for all the exercises each session using fast eccentric/ concentric movements. Blagrove (8) offers visual representations for each of the UPT and BPT exercises. 


\begin{tabular}{|c|c|c|c|c|c|c|c|c|c|c|c|c|}
\hline \multicolumn{13}{|c|}{ UPT } \\
\hline \multirow[b]{3}{*}{ Exercise } & \multirow[b]{3}{*}{ Week } & \multicolumn{11}{|c|}{ Sets $\mathrm{x}$ repetitions } \\
\hline & & \multicolumn{3}{|c|}{2 sessions/ week } & \multicolumn{8}{|c|}{3 sessions/ week } \\
\hline & & 1 & 2 & 3 & 4 & 5 & 6 & 7 & 8 & 9 & 10 & 11 \\
\hline $\mathrm{CMJ}$ - right leg & & $1 \times 5$ & $2 \times 5$ & $3 \times 5$ & $3 \times 5$ & $1 \times 5$ & $2 \times 5$ & $3 \times 5$ & $4 \times 5$ & $2 \times 5$ & $3 \times 5$ & $4 \times 5$ \\
\hline CMJ - left leg & & $1 \times 5$ & $2 \times 5$ & $3 \times 5$ & $3 \times 5$ & $1 \times 5$ & $2 \times 5$ & $3 \times 5$ & $4 \times 5$ & $2 \times 5$ & $3 \times 5$ & $4 \times 5$ \\
\hline SLJ - right leg & & $1 \times 5$ & $2 \times 5$ & $3 \times 5$ & $3 \times 5$ & $2 \times 5$ & $2 \times 5$ & $3 \times 5$ & $4 \times 5$ & $2 \times 5$ & $3 \times 5$ & $4 \times 5$ \\
\hline SLJ - left leg & & $1 \times 5$ & $2 \times 5$ & $3 \times 5$ & $3 \times 5$ & $2 \times 5$ & $2 \times 5$ & $3 \times 5$ & $4 \times 5$ & $2 \times 5$ & $3 \times 5$ & $4 \times 5$ \\
\hline Ankle hops (on the spot) - right leg & & $1 \times 6$ & $3 \times 6$ & $3 \times 6$ & $4 \times 6$ & $2 \times 6$ & $3 \times 6$ & $3 \times 6$ & $4 \times 6$ & $3 \times 6$ & $3 \times 6$ & $4 \times 6$ \\
\hline Ankle hops (on the spot) - left leg & & $1 \times 6$ & $3 \times 6$ & $3 \times 6$ & $4 \times 6$ & $2 \times 6$ & $3 \times 6$ & $3 \times 6$ & $4 \times 6$ & $3 \times 6$ & $3 \times 6$ & $4 \times 6$ \\
\hline Alternate leg bounds & & $1 \times 10$ & $1 \times 10$ & $2 \times 10$ & $3 \times 10$ & $1 \times 10$ & $2 \times 10$ & $3 \times 10$ & $4 \times 10$ & $2 \times 10$ & $3 \times 10$ & $4 \times 10$ \\
\hline Alternate-leg box push-offs (30cm box) & & $1 \times 10$ & & $2 \times 10$ & $3 \times 10$ & $1 \times 10$ & $2 \times 10$ & $3 \times 10$ & $4 \times 10$ & $2 \times 10$ & $3 \times 10$ & $4 \times 10$ \\
\hline Single leg bounds - right leg & & $1 \times 5$ & & & $2 \times 5$ & $1 \times 5$ & $2 \times 5$ & $3 \times 5$ & $4 \times 5$ & $2 \times 5$ & $3 \times 5$ & $4 \times 5$ \\
\hline Single leg bounds - left leg & & $1 \times 5$ & & & $2 \times 5$ & $1 \times 5$ & $2 \times 5$ & $3 \times 5$ & $4 \times 5$ & $2 \times 5$ & $3 \times 5$ & $4 \times 5$ \\
\hline Single leg box jumps $(22.5 \mathrm{~cm})$ - right leg & & $1 \times 5$ & & & & & $1 \times 5$ & $2 \times 5$ & $3 \times 5$ & $2 \times 5$ & $3 \times 5$ & $4 \times 5$ \\
\hline Single leg box jumps $(22.5 \mathrm{~cm})$ - left leg & & $1 \times 5$ & & & & & $1 \times 5$ & $2 \times 5$ & $3 \times 5$ & $2 \times 5$ & $3 \times 5$ & $4 \times 5$ \\
\hline Total foot contacts & & 72 & 86 & 136 & 188 & 84 & 146 & 206 & 278 & 156 & 216 & 288 \\
\hline
\end{tabular}

Table 1.11-week plyometric training program. 


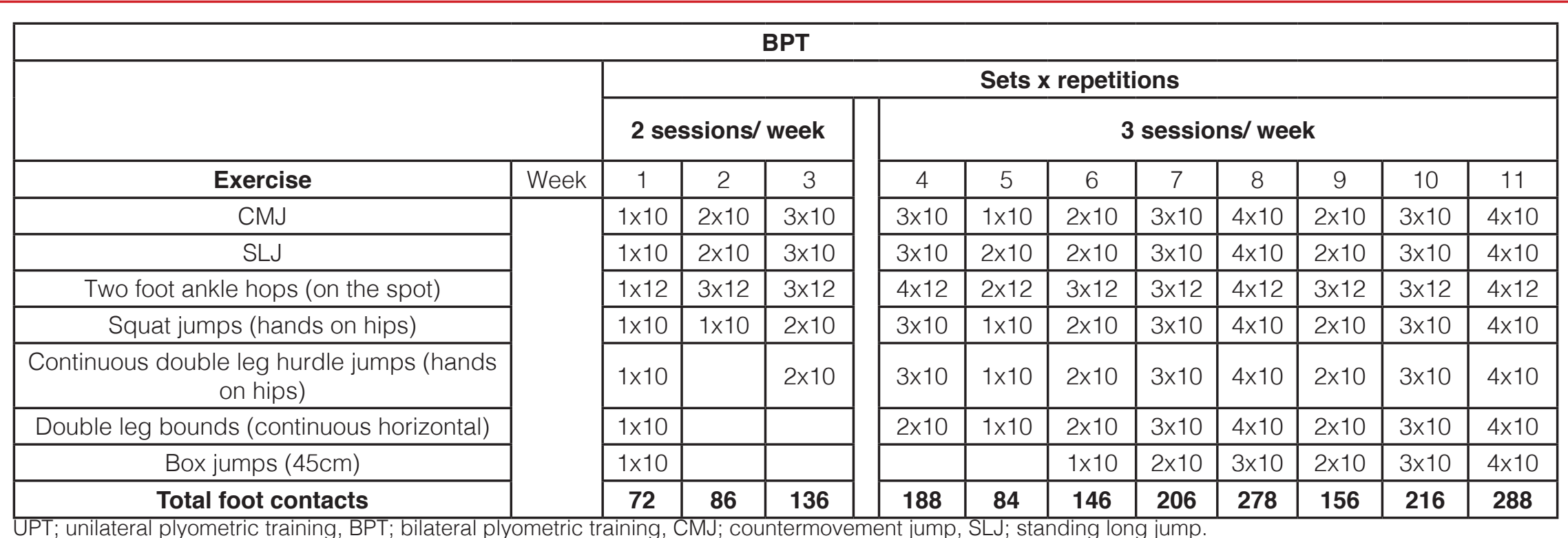

Table 1. Continued 


\section{Statistical Analysis}

Independent variables were defined in terms of the type of training: regular running training plus either UPT or BPT for the experimental groups and regular running training only for the CON group. IBM SPSS Statistics (v.22 software) was used for all statistical calculations. Parametric assumptions were met for each dependent variable including homogeneity of variance using the Levene's test for between groups and Mauchly's test of sphericity for equal variance within groups. A one-way ANOVA was used to assess between group differences in weekly km running volume. Separate two-way repeated measures ANOVAs were used to assess within and between group differences in all other dependent variables. Where significant differences were detected, multiple comparisons were made with Bonferroni correction to identify the location of main effects from the ANOVAs. To determine the magnitude of within-group change in variables, Cohen's d effect sizes (ES) with 95\% confidence intervals $(95 \% \mathrm{Cl})$ were calculated. The criteria to interpret the magnitude of the ES were 0.0-0.29 trivial, 0.30-0.59 small, 0.601.19 moderate, $1.20-1.99$ large and $>2.0$ very large (14). Within-session reliability for unilateral and bilateral isometric MVC knee extensor torque and CMJ height was determined using the three trials completed in the pre-training testing session by calculating intraclass correlation coefficients (ICC) with 95\% confidence intervals $(\mathrm{Cl})$ and coefficients of variation (CV). No significant difference $(p>0.05)$ was detected in intra-session trials for unilateral or bilateral torque or jump height with excellent reliability reported for unilateral torque $(\mathrm{ICC}=0.999[95 \% \mathrm{Cl}$ $=0.998-1.000], \mathrm{CV}=1.7 \%)$, bilateral torque (ICC = 1.000 [95\% IC $=0.999-1.000], C V=1.1 \%$, unilateral CMJ height (right limb ICC $=0.988[95 \% \mathrm{Cl}=0.977$ 0.994], CV $=5.9 \%$; left limb ICC $=0.995$ [95\%Cl = 0.990-0.997], $\mathrm{CV}=4.5 \%$ ) and bilateral CMJ height $(I C C=0.995$ [95\%IC $=0.990-0.997], C V=3.4 \%)$. The level of significance was set at $p<0.05$. All data are presented as mean $\pm \mathrm{SD}$.

\section{RESULTS}

All participants $(n=27)$ completed the 11-week training program, i.e. regular running training plus either UPT or BPT for the experimental groups, with the CON group participating only in regular running training. Training compliance was very high in both groups, with UPT participants attending 97\% and BPT participants $99 \%$ of the once weekly-supervised plyometric training sessions. No significant differ- ences $(p>0.05)$ in any dependent variables were detected in baseline data between groups (Table 2), or for mean weekly running volume across the 11week period between groups (Table 3). There was no significant change $(p>0.05)$ in body mass, VO2 max (Table 2 ), or in mean weekly running volume (Table 3) over the 11-week plyometric training period within the experimental or CON groups.

\section{$R E$, 3-km TT}

After training, the UPT group demonstrated a significant improvement in RES1 (4.9 $\pm 1.5 \%$, ES $=1.14$ $[C l=0.26-1.92], p=0.001), \operatorname{RES} 2(6.2 \pm 1.2 \%$, ES $=1.23[\mathrm{Cl}=0.33-2.01], \mathrm{p}=0.001)$ and $3-\mathrm{km}$ TT $(2.4 \pm 2.0 \%, E S=0.17[\mathrm{Cl}=-0.61-0.94], p=0.001)$ (Table 2). Similarly, BPT groups also demonstrated a significant improvement in RES1 $(5.0 \pm 0.7 \%$, ES $=1.20[\mathrm{Cl}=0.31-1.98], \mathrm{p}=0.001), \operatorname{RES} 2(4.7 \pm$ $2.0 \%, E S=1.37[\mathrm{Cl}=0.45-2.16], p=0.001)$ and $3-\mathrm{km}$ TT $(2.5 \pm 1.1 \%, \mathrm{ES}=0.26[\mathrm{Cl}=-0.53-1.02]$, $\mathrm{p}=0.001$ ) (Table 2). In the CON group there was no significant increase in RES1 $(0.1 \pm 1.4 \%$, ES = $0.00[\mathrm{Cl}=-0.78-0.78], \mathrm{p}=0.805), \operatorname{RES} 2(0.9 \pm$ $1.0 \%, E S=0.36[\mathrm{Cl}=-0.44-1.13], p=0.806)$ and $3-\mathrm{km}$ TT $(0.2 \pm 0.2 \%, E S=0.01[\mathrm{Cl}=-0.77-0.78], \mathrm{p}$ $=0.717$ ) (Table 2). No statistically significant differences in any measure were found between groups $(p>0.05)$. RER of $<1.0$ was recorded during all RE trials, indicative that no VO2 slow component was evident and that any oxygen consumption was for locomotion rather than metabolite removal.

\section{Unilateral and Bilateral Isometric MVC Knee Exten- sor Torque}

No significant differences were observed after the training intervention period for the bilateral isometric MVC knee extensor torque in the UPT $(-1.8 \pm 11.4 \%$, $\mathrm{ES}=0.11[\mathrm{Cl}=-0.67-0.88], \mathrm{p}=0.482)$, BPT $(-2.4$ $\pm 12.3 \%, \mathrm{ES}=0.10[\mathrm{Cl}=-0.68-0.87], \mathrm{p}=0.380$ ) or $\operatorname{CON}(-2.4 \pm 9.0 \%, E S=0.14[\mathrm{Cl}=-0.64-0.91], p=$ 0.331 ) groups (Table 2). However, unilateral isometric MVC knee extensor torque for the UPT group significantly improved after the training program (10.8 $\pm 15.1 \%, E S=0.41[\mathrm{Cl}=-0.39-1.18], \mathrm{p}=0.009)$ (Table 2) with no significant change identified within the BPT $(-1.1 \pm 14.0 \%, E S=0.12[\mathrm{Cl}=-0.66-0.89]$, $\mathrm{p}=0.445)$ or $\mathrm{CON}(2.3 \pm 12.9 \%$, ES $=0.03[\mathrm{Cl}=$ $-0.80-0.75], p=0.853$ ) groups (Table 2 ). No statistically significant differences in any measure were found between groups ( $p>0.05)$. 


\begin{tabular}{|c|c|c|c|c|c|c|}
\hline & \multicolumn{6}{|c|}{ Mean + SD $(95 \%$ Cl) group data } \\
\hline & \multicolumn{2}{|c|}{ UPT $(n=9)$} & \multicolumn{2}{|c|}{$\mathrm{BPT}(\mathrm{n}=9)$} & \multicolumn{2}{|c|}{$\operatorname{CON}(n=9)$} \\
\hline & WO & W11 & WO & W11 & WO & W11 \\
\hline Physiology & & & & & & \\
\hline \multirow{2}{*}{ Body mass (kg) } & $69.3 \pm 14.7$ & $69.7 \pm 14.9$ & $81.5 \pm 19.5$ & $81.6 \pm 19.9$ & $72.2 \pm 6.5$ & $71.5 \pm 5.9$ \\
\hline & $(59.2-79.3)$ & $(59.6-79.9)$ & $(71.4-91.5)$ & $(71.5-91.8)$ & (62.2-82.2) & $(61.3-81.6)$ \\
\hline \multirow{2}{*}{$\mathrm{VO}_{2} \max (\mathrm{ml} \cdot \mathrm{kg}-1 \cdot \min -1)$} & $49.8 \pm 7.2$ & $49.8 \pm 7.1$ & $45.5 \pm 3.8$ & $45.3 \pm 3.6$ & $48.6 \pm 3.8$ & $48.8 \pm 3.9$ \\
\hline & $(46.2-53.3)$ & $(46.3-53.3)$ & $(41.9-49.1)$ & $(41.7-48.8)$ & $(44.9-52.2)$ & $(45.2-52.3)$ \\
\hline \multirow{2}{*}{ RES1 (kj.kg-1.km-1) } & $4.23 \pm 0.23$ & $4.02 \pm 0.12^{\star \star}$ & $4.28 \pm 0.18$ & $4.07 \pm 0.17^{\star \star}$ & $4.13 \pm 0.05$ & $4.13 \pm 0.07$ \\
\hline & $(4.0-4.4)$ & $(3.9-4.1)$ & $(4.1-4.4)$ & $(3.9-4.2)$ & $(4.1-4.2)$ & $(4.1-4.2)$ \\
\hline \multirow{2}{*}{ RES2 (kj.kg-1.km-1) } & $4.34 \pm 0.29$ & $4.06 \pm 0.14^{\star \star}$ & $4.21 \pm 0.16$ & $4.01 \pm 0.13^{\star \star}$ & $4.16 \pm 0.09$ & $4.12 \pm 0.03$ \\
\hline & $(4.1-4.6)$ & $(4.0-4.2)$ & $(4.1-4.3)$ & $(4.0-4.1)$ & $(4.1-4.2)$ & $(4.1-4.2)$ \\
\hline \multirow{2}{*}{\multicolumn{7}{|c|}{$\begin{array}{c}\text { Strength } \\
M V C \\
\end{array}$}} \\
\hline & & & & & & \\
\hline \multirow{2}{*}{ Unilateral dominant leg (Nm) } & $163.9 \pm 48.3$ & $183.7 \pm 47.4^{\star *}$ & $197.3 \pm 50.0$ & $191.9 \pm 41.7$ & $181.2 \pm 49.9$ & $182.5 \pm 42.8$ \\
\hline & $(129.9-197.9)$ & $(153.3-213.9)$ & $(163.3-231.3)$ & $(161.6-222.2)$ & $(147.2-215.2)$ & $(152.1-212.8)$ \\
\hline \multirow{2}{*}{ Bilateral (Nm) } & $321.6 \pm 97.3$ & $311.6 \pm 86.2$ & $379.9 \pm 126.9$ & $367.4 \pm 120.8$ & $334.8 \pm 110.2$ & $321.0 \pm 84.1$ \\
\hline & $(244.4-398.7)$ & $(243.8-379.3)$ & $(302.8-457.1)$ & $(299.6-435.1)$ & $(257.7-411.9)$ & $(253.2-388.7)$ \\
\hline CMJ & & & & & & \\
\hline \multirow{2}{*}{ Bilateral (cm) } & $31.6 \pm 8.3$ & $33.9 \pm 8.8^{\star \star}$ & $29.7 \pm 6.1$ & $33.4 \pm 7.2^{\star \star}$ & $32.2 \pm 10.6$ & $32.1 \pm 10.8$ \\
\hline & $(25.7-37.4)$ & $(27.7-40.1)$ & $(23.8-35.6)$ & $(27.2-39.7)$ & $(26.3-38.1)$ & $(25.9-38.3)$ \\
\hline \multirow{2}{*}{ Unilateral right leg (cm) } & $17.1 \pm 5.0$ & $19.2 \pm 5.1^{\star \star}$ & $15.3 \pm 3.5$ & $17.7 \pm 3.8^{\star *}$ & $15.9 \pm 6.0$ & $16.0 \pm 6.1$ \\
\hline & $(13.7-20.5)$ & $(15.7-22.7)$ & $(11.9-18.7)$ & $(14.2-21.2)$ & $(12.5-19.3)$ & $(12.5-19.5)$ \\
\hline \multirow{2}{*}{ Unilateral left leg (cm) } & $17.0 \pm 5.2$ & $19.2 \pm 4.8^{\star \star}$ & $16.1 \pm 4.4$ & $18.3 \pm 4.4^{\star \star}$ & $15.8 \pm 5.9$ & $16.0 \pm 5.9$ \\
\hline & $(13.4-21.0)$ & $(15.7-22.7)$ & $(12.5-19.7)$ & $(14.8-21.8)$ & $(12.2-19.3)$ & $(12.5-19.4)$ \\
\hline Performance & & & & & & \\
\hline \multirow{2}{*}{ 3-km TT performance (min:s) } & $13: 19 \pm 1: 45$ & $13: 01 \pm 1: 47^{\star \star}$ & $13: 48 \pm 1: 25$ & $13: 27 \pm 1: 18^{\star \star}$ & $13: 32 \pm 1: 41$ & $13: 31 \pm 1: 41$ \\
\hline & $(12: 10-14: 20)$ & $(11: 50-14: 10)$ & $(12: 40-14: 50)$ & $(12: 10-14: 40)$ & $(12: 20-14: 40)$ & $(12: 20-14: 40)$ \\
\hline
\end{tabular}

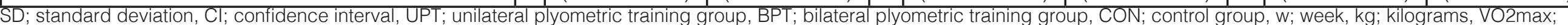

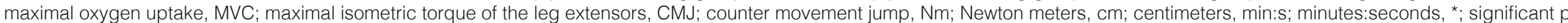
$<0.05$ within groups, ${ }^{* *}$; significant $p<0.01$ within groups.

Table 2. Physiological, strength and performance values for weeks 0 and 11 . 


\begin{tabular}{|c|c|c|c|c|c|c|}
\hline & \multicolumn{6}{|c|}{ Mean + SD $(95 \% \mathrm{Cl})$ group data } \\
\hline & \multicolumn{2}{|c|}{ UPT $(n=9)$} & \multicolumn{2}{|c|}{$\operatorname{BPT}(n=9)$} & \multicolumn{2}{|c|}{$\operatorname{CON}(n=9)$} \\
\hline & WO & W11 & W0 & W11 & W0 & W11 \\
\hline \multirow{2}{*}{ Weekly running volume (km) } & $\begin{array}{c}34.9 \pm \\
3.5\end{array}$ & $\begin{array}{c}35.5 \pm \\
2.8\end{array}$ & $\begin{array}{c}35.5 \pm \\
4.1\end{array}$ & $\begin{array}{c}33.1 \pm \\
4.6\end{array}$ & $\begin{array}{c}33.6 \pm \\
4.9\end{array}$ & $\begin{array}{c}34.9 \pm \\
4.7\end{array}$ \\
\hline & $\begin{array}{c}(32.2- \\
37.7)\end{array}$ & $\begin{array}{l}(33.3- \\
37.6)\end{array}$ & $\begin{array}{c}(32.3- \\
38.6)\end{array}$ & $\begin{array}{c}(29.6- \\
36.6)\end{array}$ & $\begin{array}{c}(29.9- \\
37.4)\end{array}$ & $\begin{array}{c}(31.3- \\
38.5)\end{array}$ \\
\hline
\end{tabular}

SD; standard deviation, Cl; confidence interval, UPT; unilateral plyometric training group, BPT; bilateral plyometric training group, CON; control group, w; week, $\mathrm{km}=$ kilometers.

Table 3. Weekly running volume values for weeks 0 and 11.

\section{Unilateral and Bilateral CMJ}

Following the training intervention, UPT and BPT groups showed a significant improvement in all 3 CMJ measures: unilateral right (UPT $13.7 \pm 12.2 \%$, $\mathrm{ES}=0.42[\mathrm{Cl}=-0.38-1.18], \mathrm{p}=0.001 ; \mathrm{BPT} 15.9$ $\pm 9.9 \%, E S=0.64[\mathrm{Cl}=-0.18-1.40], \mathrm{p}=0.001)$, unilateral left (UPT $16.2 \pm 18.7 \%, E S=0.44[\mathrm{Cl}=$ $-0.36-1.21], p=0.001 ;$ BPT $14.9 \pm 9.4 \%, E S=0.51$ $[\mathrm{Cl}=-0.30-1.27], \mathrm{p}=0.001)$ and bilateral (UPT 7.7 $\pm 10.1 \%, E S=0.27[C l=-0.52-1.04], p=0.002$; BPT $12.6 \pm 6.1 \%$, ES $=0.56[\mathrm{Cl}=-0.25-1.33], \mathrm{p}$ $=0.001$ ) (Table 2). In the CON group there was no significant change in unilateral right $(0.5 \pm 4.1 \%$, $\mathrm{ES}=0.02[\mathrm{Cl}=-0.76-0.79], \mathrm{p}=0.815)$, unilateral left $(1.6 \pm 5.6 \%, E S=0.04[\mathrm{Cl}=-0.74-0.81], p=$ $0.668)$, or bilateral CMJ measures $(-0.6 \pm 3.1 \%$, ES $=0.01[\mathrm{Cl}=-0.77-0.79], \mathrm{p}=0.873$ ) (Table 2). No statistically significant differences in any measure were found between groups ( $p>0.05$ ).

\section{DISCUSSION}

The aim of this study was to compare the effect of an 11-week UPT versus BPT program on RE and TT endurance running performance in recreationally trained distance runners. The main finding of the present study indicates that very high volume UPT and BPT significantly improved RE, 3-km TT run performance and explosive strength (jump height) to a similar degree in recreational endurance runners. These results suggest that to optimize endurance running performance UPT or BPT should be added concurrently to a regular run training program.

Both plyometric groups showed a significant improvement in $3-\mathrm{km}$ TT performance $(2.4-2.5 \%$, ES $=0.17-0.26)$ with no significant difference between groups. These results are consistent with previous research albeit in shorter time frames (6-9 weeks), in competitive distance runners that noted similar improvements in TT run performance after bilateral or unilateral and bilateral plyometric training $(5,22,23,25,28)$. A recent study (23) examined the effects of plyometric training on TT run performance. Twenty-five trained runners included 2-3 sessions of high volume, low-moderate intensity unilateral and bilateral plyometric exercises per week over 6 weeks to a regular endurance training program. The authors found a significant improvement in 3-km TT performance $(2.6 \%)$. Other authors $(5,25)$ reported marginally greater magnitudes of improvement in TT runs (5.0\% \& 3.9\% respectively) after a 6-8 week low-volume, high intensity bilateral plyometric training period in moderately to well-trained distance runners $(E S=0.4)$. Participants in the current study performed a very high volume ( $>200$ foot contacts per session), low intensity unilateral or bilateral plyometric training program. Whilst foot contact volume in the present study was unusually high for both UPT and BPT groups (weeks 7,8,10 11, Table 3) when compared to 30-228 foot contacts per session reported in a recent systematic review (7), participants did not report any injuries. These results support existing research reporting improvements in distance run performance through a structured plyometric training program, although exercise intensity may be of greater importance than either mode (UPT versus BPT) or training volume. The present study shows that either mode of plyometric training represents a time-efficient and cost effective (minimal equipment requirements) way to train without increasing weekly running volume.

In the present study, both plyometric groups showed a significant improvement in RE across the two running speeds (4.9-5.6\%, ES $=1.1-1.3)$ with no significant difference between groups. In a recent study (5), eleven moderately to well-trained endurance runners added one additional session of low-volume, high intensity bilateral plyometric training per week over 8-weeks to their usual endurance run training. They reported a large improvement in RE (7\%, ES 
$=1.01$ ) whereas peak VO2 remained unchanged.

Previous plyometric training programs used to enhance RE have demonstrated lower magnitudes of improvement (3.0-6.0\%) after 6-9 weeks of 2-3 moderate to high-volume, low to moderate intensity combine unilateral and bilateral plyometric training sessions per week in moderately to well-trained distance runners $(27,28,31)$ with no change in VO2max. Various factors may have contributed to the magnitudes of change differences in RE between low-volume, high intensity versus high volume, low intensity based plyometric training programs. Morphological (muscle-tendon unit properties) and neural (motor unit recruitment, intermuscular coordination) changes to the musculotendinous system (4) may have been influenced by the type of plyometric exercise (18). It has been proposed that improvements in explosive strength can be attributed to an increase in motor unit recruitment allowing lower limb muscles to resist eccentric loading during stance of the running gait cycle thereby facilitating a more energy efficient isometric contraction $(7,11,26)$. It is possible that such fast stretch shortening cycle plyometric exercises used by Berryman et al. (5) enhanced RE to a greater degree than that seen in the present and previous studies as a result of improved motor unit recruitment and the development of a more optimal mechanical stiffness of the musculotendinous system. Further research is warranted to determine the exact mechanisms from different types of muscle contractions as a result of explosive resistance and plyometric training on RE.

In the present study, only UPT significantly improved unilateral isometric MVC knee extensor torque $(10.8 \%, E S=0.41)$ after training. Previous research $(9,18,22,30)$ demonstrates equivocal findings of the change in maximal isometric strength of the leg extensors (0-10\%) where the impact of neuromuscular characteristics on RE and endurance performance has been investigated over short durations (6-9 weeks). From a neuromuscular perspective, an increase in absolute motor unit recruitment as a result of explosive strength training would lead to a lower relative intensity per motor unit thereby delaying the activation of metabolically inefficient type II fibers during distance running $(4,7,11)$. Lower relative force outputs that are commonly observed during bilateral strength and explosive strength training $(6,13,17)$ may explain the lack of significant change in isometric MVC knee extensor torque in the BPT group.

Despite both plyometric groups significantly improving all CMJ measures after 11 weeks with no signif- icant difference between groups the magnitude of improvement in bilateral CMJ from BPT (12.6\%, ES $=0.56)$ was greater than that following UPT $(7.7 \%$, $E S=0.27)$. Theoretically, an enhanced stretch shortening cycle function as evidenced from the bilateral CMJ measure would result from higher movement velocities and greater absolute force outputs generated through BPT $(17,18)$. The most important morphological adaptation from plyometric training cited in the literature $(3,11,28)$ as previously mentioned seems to be an optimal stiffness and elasticity of the muscle-tendon unit that is achieved through a reduction in the magnitude and velocity of muscle shortening thereby allowing muscle fibers to better resist eccentric loading and remain in an energy efficient isometric state. Conceivably, this would explain the improved RE and 3-km TT run performance observed from the BPT group.

It must be acknowledged that the present study is not without limitations. Only one of the weekly plyometric training sessions was supervised and endurance training for all participants was self-reported over the 11-week period, although weekly contact was continued to ensure training was maintained throughout the program. A second limitation was that the phase of the menstrual cycle when testing took place was not controlled for in the female participants who did not use a hormonal contraceptive. Similarly, the use of the treadmill during the 3-km TT may be problematic because over ground running would likely offer greater validity and reliability as a participant approaches exhaustion where speed and rhythm are easier to change. In addition, treadmill speeds for RE were not selected relative to each participants physiological capabilities, possibly compromising the external validity of the findings. Finally, randomizing the order of the isometric MVC and CMJ tests and selecting a more effective knee angle for the CMJ tests (17) would have enhanced the validity of the study.

\section{PRACTICAL APPLICATIONS}

The ultimate goal of a distance runner's training program is to enhance performance and minimize injury risk. The purpose of the present study was to compare the effects of UPT versus BPT, which were matched for volume and intensity on RE and TT run performance in recreationally trained male and females distance runners. The results indicate that BPT may be safer due to a reduced injury risk associated with the bilateral force deficit $(13,17,21)$, and is equally effective as UPT at enhancing distance 
running performance. A reduction in relative lower limb impact to joint and tissue structures from bilateral jumping could be of greater benefit to runners undertaking high volume weekly endurance training that have a greater exposure to injury risk associated with high mileage running (21). Therefore, coaches should plan a periodized BPT program that emphasizes high volume and low intensity exercises to support the optimization of performance in recreationally trained male and female distance runners. 


\section{ACKNOWLEDGEMENTS}

The authors would like to thank all the runners that took part in the study. The authors have no conflicts of interest that are relevant to the contents of this article. No funding was obtained to support this study.

\section{REFERENCES}

1. American College of Sports Medicine. ACSM'S Guidelines for Exercise Testing and Prescription. 9th ed. Baltimore: Williams \& Wilkins, 2014

2. Barnes, KR, Kilding, AE. Running Economy: measurement, norms and determining factors. Sports Med 1: 1-15, 2015.

3. Barnes, KR and Kilding, AE. Strategies to improve running economy. Sports Med 45: 37-56, 2015.

4. Beattie, K, Carson, BP, Lyons, M, Rossiter, A, Kenny, IC. The effect of strength training on performance indicators in distance runners. J Strength Cond Res 31: 9-23, 2017.

5. Berryman, N, Maurel, D, and Bosquet, L. Effect of plyometric vs. dynamic weight training on the energy cost of running. J Strength Cond Res 24: 1818-1825, 2010.

6. Bogdanis, GC, Tsoukos, A, Kaloheri, O, et al. Comparison between unilateral and bilateral plyometric training on single and double leg jumping performance and strength. J Strength Cond Res 10: 1-8, 2017.

7. Blagrove, RC, Howatson, G, Hayes, PR. Effects of strength training on the physiological determinants of middle- and long-distance running performance: A systematic review. Sports Med 48: 1117-1149, 2017.

8. Blagrove, RC. Strength and conditioning for endurance running. Crowood, 2015.

9. Ferrauti, A, Bergermann, M, Fernandez-Fernandez, J. Effects of a concurrent strength and endurance training on running performance and running economy in recreational marathon runners. J Strength Cond Res 24: 2770-2778, 2010.

10. Fletcher, JR, Esau, SP, MacIntosh, BR. Economy of running: beyond the measurement of oxygen uptake. J Appl Physiol 107: 1918-1922, 2009.

11. Fletcher, JR, Maclntosh, BR. Running economy from a muscle energetics perspective. Frontiers in Physiol 433: $1-15,2017$.

12. Fletcher, JR, Maclntosh BR. Theoretical considerations for muscle-energy savings during distance running. J Biomechanics 73: 73-79, 2018.

13. Gonzalo-Skok, O, Tous-Fajardo, J, Suarez-Arrones, L, et al. A. Single-leg power output and between-limbs imbalances in team-sport players: Unilateral versus bilateral combined resistance training. Int J Sports Physiol Perform. 12: 106-114, 2017.

14. Hopkins, WG, Marshall, SW, Batterham, AM, Hanin, J. Progressive statistics for studies in sports medicine and exercise science. Med Sci Sports Exerc 41: 3-12, 2009.

15. Joyner, MJ, Coyle, EF. Endurance exercise performance: the physiology of champions. J Physiol 586: 34-44, 2008.

16. Jung, AP. The impact of resistance training on distance running performance. Sports Med 33: 539-552, 2003.

17. Makaruk, H, Wincherster, JB, Sadowski, J, Czaplicki, A. Sacewicz, T. Effects of unilateral and bilateral plyometric training on power and jumping ability in women. J Strength Cond Res 25: 1-8, 2011.
18. Markovic, G, Milkulic, P. Neuro-musculoskeletal and performance adaptations to lower-extremity plyometric training. Sports Med 40: 859-895, 2010.

19. McCurdy, KW, Langford, GA, Doscher, MW, Wiley, LP, Mallard, KG. The effects of short-term unilateral and bilateral lower-body resistance training on measures of strength and power. J Strength Cond Res 19: 9-15, 2005

20. Moore, IS. Is there an economical running technique? A review of modifiable biomechanical factors affecting running economy. Sports Med 46: 793-807, 2016.

21. Mucha, MD, Caldwell, W, Schlueter, EL, Walters C, Hassen, A. Hip abductor strength and lower extremity running related injury in distance runners: a systematic review. J Sci Med Sport 20: 349-55, 2017.

22. Paavolainen L, Häkkinen K, Hämäläinen I, Nummela $A$, Rusko, $\mathrm{H}$. Explosive strength training improves $5-\mathrm{km}$ running time by improving running economy and muscle power. J Appl Physiol 86: 1527-1533, 1999.

23. Pellegrino, J, Ruby, BC, Dumke, CL. Effect of plyometrics on the energy cost of running and $\mathrm{MHC}$ and titin isoforms. Med Sci Sports Exerc 48: 49-56, 2016.

24. Ramirez-Campillo, R, Burgos, CH, Henriquez-Olguin, C, et al. Effect of unilateral, bilateral, and combined plyometric training on explosive and endurance performance of young soccer players. J Strength Cond Res 29: 13171328, 2015.

25. Ramírez-Campillo, R, Álvarez, C, Henríquez-Olguín, C, et al. Effects of plyometric training on endurance and explosive strength performance in competitive middle-and long-distance runners. J Strength Cond Res 28: 97-104, 2014.

26. Sale, DG. Neural adaptation to resistance training. Med Sci Sports Exerc 20: 135-145, 1988.

27. Saunders, PH, Telford, RD, Pyne, D, Peltola, EM, Cunningham, RB. Short-term plyometric training improves running economy in highly trained middle and long distance runners. J Strength Cond Res 20: 947-954, 2006.

28. Spurrs, RW, Murphy, AJ, Watsford, ML. The effect of plyometric training on distance running performance. Eur $\mathrm{J}$ Appl Physiol 89: 1-7, 2003.

29. Storen, O, Helgerud, J, Stoa, EM, Hoff, J. Maximal strength training improves running economy in distance runners. $J$ Sports Sci Med 40: 1089-1094, 2008.

30. Taipale, RS, Mikkola, J, Vesterinen, V, Nummela, A, Häkkinen, K. Neuromuscular adaptations during combined strength and endurance training in endurance runners: maximal versus explosive strength training or a mix of both. Eur J Appl Physiol 113: 325-335, 2013.

31. Turner, AM, Owings, M, Schwane, JA. Improvement in running economy after 6 weeks of plyometric training. $J$ Strength Cond Res 17: 60-67, 2003. 